\title{
Relationship Between Anthropometric Parameters and Intelligence in Preschool Children from Rural Konkan
}

\author{
Patil Suvarna $N^{1}$, Joglekar Charudatta ${ }^{2}$, Sonavane Swati ${ }^{3}$,Chavan Rupali ${ }^{3}$, Bhat Pallavi $R^{3}$, Mohite Rachana ${ }^{3}$, \\ Deorukhakar Pralobhana P3, Jadhav Dnyaneshwar $A^{3}$, Dervankar Omkar $A^{3}$

\begin{abstract}
${ }^{1}$ BKL Walawalkar Hospital and Rural Medical College, Sawarde,
Taluka-Chiplun District-Ratnagiri, Maharashtra, India.

${ }^{2}$ Statistics Unit, Regional Centre for Adolescent Health and Nutrition,

BKL Walawalkar Hospital and Rural Medical College, Sawarde, Chiplun, Ratnagiri, Maharashtra, India.

${ }^{3}$ Regional Centre for Adolescent Health and Nutrition,

BKL Walawalkar Hospital and Rural Medical College, Sawarde, Chiplun, Ratna giri, Maharashtra, India.
\end{abstract}

\begin{abstract}
Aim: To study the association between anthropometric parameters and intelligence in preschool children from Rural KONKAN. Method: Children between 3 to7 years of age were examined for anthropometry, dietary recall, and Intelligence (Intelligent Quotient-IQ) assessment from rural anganwadis. The IQ test was performed by clinical psychologists using Binet-Kamat test of intelligence (version 4). Nutritional information was collected from 24- hour dietary recall and food diversity. Results: Results were interpreted using Prorated IQ. We studied 159 ( 82 boys, 78 girls), out of which 15 (9.6\%) had a higher IQ. 25 (15.8\%) were born LBW. Anthropometry classification showed that $61(38.4 \%)$ were stunted, and 25(15.7\%) were wasted. According to IOTF, 72 (46\%) were thin, 83(52\%) were healthy, and $3(2 \%)$ were overweight. We found that there is no significant difference in IQ with respect to anthropometric parameters, birth weight, and nutritional status. Conclusion: We could not find any association of anthropometric parameters with IQ despite the high prevalence of malnutrition.
\end{abstract}

KEYWORDS: Malnutrition; IQ; India; Rural.

\section{INTRODUCTION}

$\longrightarrow$ ognitive development helps children to think about and understand the world around them. The brain plays a vital role in cognitive development. Cognitive ability is intelligence quotient (IQ), which is a detailed assessment of reason, language, and memory.

A report in 2016 on child cognitive development from South Africa identified significant risk factors as well as protective factors [1]. A review by Almond and Currie discusses the impact of intrauterine and early childhood environment on a child's health in adulthood [2].

According to a report in 2017 , India's under-five mortality rate had fallen by $66 \%$ since 1990 . This is a considerable amount of progress, though it still falls short of current goals. It means many infants survive and face challenges in their future life.

Premature delivery carries a great risk for newborn infants. Besides the increased mortality rate and increased incidence of morbidities, prematurity is a significant risk factor for the future neurodevelopmental delay. Cognitive impairment had been reported in about $40 \%$ of meager birth weight (VLBW) infants at school age. In comparison with term infants, VLBW infants are more likely to have lower scores in executive functions and suboptimal attentive skills [3].

Low birth weight (LBW), a proxy for IUGR, is

Correspondence: Dr Suvarna Patil, Medical Director, BKL Walawalkar Hospital and Rural Medical College, Sawarde,

Chiplun, Ratnagiri, Maharashtra, India. E-mail: dr.suvarnanpatil@gmail.com

eISSN: 2395-0471

pISSN: 2521-0394

DOI: $10.31878 /$ ijcbr.2020.62.08
(C) Authors; 2020. (CC BY-NC-SA 4.0)

This is an Open Access article which permits unrestricted

non-commercial use, provided the original work is properly cited. 
associated with poor cognitive development [4]. Poverty can have a negative impact on cognitive development, but most of the studies have been carried out in urban populations [5].

With this background, we have studied intelligence in rural children with poor socioeconomic status, and we have tried to explore the correlation of body composition with intelligence.

Our objective was to investigate anthropometry and cognition (IQ) in rural preschool children from Anganwadi in KONKAN region of Maharashtra. Anganwadi is a type of rural mother and childcare center in India.

\section{Material And Methodology}

Study design: Descriptive study

Ethical approval: Village authorities gave the written permission to study the children in anganwadis. Informed written consent was obtained from either parent of the selected child. Ethical approval was granted by the Ethics committee of BKL Walawalkar Rural Medical College and Hospital. ( Reference no: EC/755/ INST/MH/2015/RR-18).

Study duration and time frame: The study was conducted between 1st Jan - 30th June 2019, i.e., six months

Study location: The study was carried out at BKL Walawalkar Hospital Dervan situated in Ratnagiri district Maharashtra, India.

Study population: Inclusion criteria: Children were enrolled from 10 different anganwadis around $50 \mathrm{~km}$ from the hospital. We included 3-6 years old healthy children from anganwadis.

Exclusion criteria: Those with severe physical or mental disorders were excluded.

Sample size: 159 children were studied.

Methodology: These children were examined for anthropometry, dietary recall, and cognitive assessment. The birth weight data were collected from the antenatal cards \& Anganwadi records. Nutritional information was obtained from 24hour dietary recall and food diversity. Cognitive (IQ) testing was a significant activity; hence, we selected rural anganwadis having a separate room. This created a conducive environment for the child to undergo the examination.

IQ assessment was performed by Binet-Kamat test (BKT) of intelligence (version 4) [6]. This test is an Indian adaptation, a modified version of the Stanford Binet Scale measuring the intelligence of Indian children. It is an age scale where the tests are grouped into age levels extending from 3 years to a superior adult level. Each age level consists of six tests. The analysis includes both verbal and performance tests. It provides an estimate of Mental Age (MA) and IQ from 3-22 years. There are six main cognitive factors (Language, Memory, Conceptual Thinking, Reasoning, Visual Motor, and Social Intelligence) and five sub cognitive factors (Meaningful Memory, NonMeaningful Memory, Non-Verbal reasoning, Verbal Reasoning, Numerical Reasoning). The reliability of the test is reportedly above 0.7 , and the validity of this test for healthy children against the estimation of intelligence quotient by teachers is 0.5 .

We selected BKT as it was cost-effective, easy to administer, takes less time, but it has not been updated since 1960. This issue has been discussed by Rupesh \& Kumble [7], and a prorated IQ using the Flynn effect has been suggested as a solution. So the analysis was done according to the prorated IQ score. StanfordBinet Fifth Edition (SB5) classification was used for analysis [8].

Statistical Methods: Data was presented as mean (standard deviation) and as percentages for frequencies. The chi-square test made a comparison of categorical outcomes between groups, and that of continuous outcomes was by t-test. Statistical analysis was performed using SPSS 25.0 (SPSS Inc., Chicago.

\begin{tabular}{|l|l|}
\hline $\begin{array}{l}\text { IQ Range } \\
\text { (deviation IQ) }\end{array}$ & IQ Classification \\
\hline $145-160$ & Very gifted or highly advanced \\
\hline $130-144$ & Gifted or very advanced \\
\hline $120-129$ & Superior \\
\hline $110-119$ & High average \\
\hline $90-109$ & Average \\
\hline $80-89$ & Low average \\
\hline $70-79$ & Borderline impaired or delayed \\
\hline $55-69$ & Mildly impaired or delayed \\
\hline $40-54$ & Moderately impaired or delayed \\
\hline
\end{tabular}

\section{RESULTS}

Results were interpreted using Prorated IQ. We studied 159 (82 boys, 78 girls) out of which, 15 (9.6\%) had higher IQ levels. 25 (15.8\%) were born LBW. Anthropometry classification showed that $61(38.4 \%)$ were stunted and 25(15.7\%) were wasted. According to the International Obesity Task Force (IOTF), 72 (46\%) were thin, 83(52\%) were normal, and $3(2 \%)$ were overweight.

$90 \%$ of scores fall within two standard deviations (between 80 and 129). Outliers beyond those points represent only a small portion of the population, which means that only a small percentage of children have a very high IQ (above 129). 
Table 1. Analysis of IQ and calculation of Prorated IQ

\begin{tabular}{|l|l|l|}
\hline IQ & ORIGINAL (\%) & PRORATED (\%) \\
\hline VERY GIFTED & $9(5.6)$ & $2(1.37)$ \\
\hline GIFTED & $15(9.4)$ & $13(8.1)$ \\
\hline SUPERIOR & $24(15.0)$ & $19(11.9)$ \\
\hline HIGH & $48(30)$ & $56(35)$ \\
\hline AVERAGE & $58(36.3)$ & $66(41.3)$ \\
\hline LOW AVERAGE & $5(3.1)$ & $3(1.9)$ \\
\hline
\end{tabular}

Table 2. Association between IQ and anthropometric parameters. (\%)

\begin{tabular}{|c|c|c|c|c|c|c|}
\hline IQ & $\begin{array}{c}\text { Wasting } \\
25 \\
(15.6)\end{array}$ & $\begin{array}{c}\text { Stun } \\
\text { ted } \\
61 \\
(38)\end{array}$ & $\begin{array}{c}\text { Under } \\
\text { weight } \\
21 \\
(13.12)\end{array}$ & $\begin{array}{c}\text { Normal } \\
75 \\
(47.5)\end{array}$ & $\begin{array}{c}\text { Head } \\
\text { Circum } \\
\text { ference } \\
\text { mean } \\
(\text { SD })\end{array}$ & $\begin{array}{c}\text { LBW } \\
(15.8)\end{array}$ \\
\hline $\begin{array}{c}\text { Very } \\
\text { gifted }\end{array}$ & $\begin{array}{c}1 \\
(4)\end{array}$ & $\begin{array}{c}1 \\
(1.6)\end{array}$ & $1(4.8)$ & $1(1.3)$ & $\begin{array}{c}47.75 \\
(0.35)\end{array}$ & 0 \\
\hline Gifted & 0 & $\begin{array}{c}4 \\
(6.6)\end{array}$ & 0 & $5(6.7)$ & $\begin{array}{c}47.26 \\
(1.68)\end{array}$ & $1(4)$ \\
\hline Superior & 4 & $\begin{array}{c}5 \\
(21.1)\end{array}$ & $\begin{array}{c}4 \\
(8.2)\end{array}$ & $5(6.7)$ & $\begin{array}{c}47.47 \\
(1.59)\end{array}$ & $2(8)$ \\
\hline High & 11 & 24 & 7 & 31 & 47.26 & $6(24)$ \\
$(44)$ & $(39.3)$ & $(33.3)$ & $(41.3)$ & $(1.74)$ & \\
\hline Average & 9 & 26 & 9 & $33(44)$ & $\begin{array}{c}47.45 \\
(1.51)\end{array}$ & $15(60)$ \\
\hline $\begin{array}{c}\text { Low } \\
\text { average }\end{array}$ & 0 & $1(1.6)$ & 0 & 0 & $\begin{array}{c}47.30 \\
(1.13)\end{array}$ & $1(4)$ \\
\hline
\end{tabular}

Table 2 shows $\mathrm{n}(\%)$ of wasting, stunted, underweight, normal and LBW and mean (SD) for head circumference. Stunting refers to those below -2 SD score for height (gender, age) using the World Health Organization (WHO) criteria. Wasting refers to those below $-2 \mathrm{SD}$ for the weight for height (gender, age) and underweight refers to those below -2 SD score for the weight (gender, age) using WHO criteria. Usually refers to those who neither stunted nor wasted nor underweight.

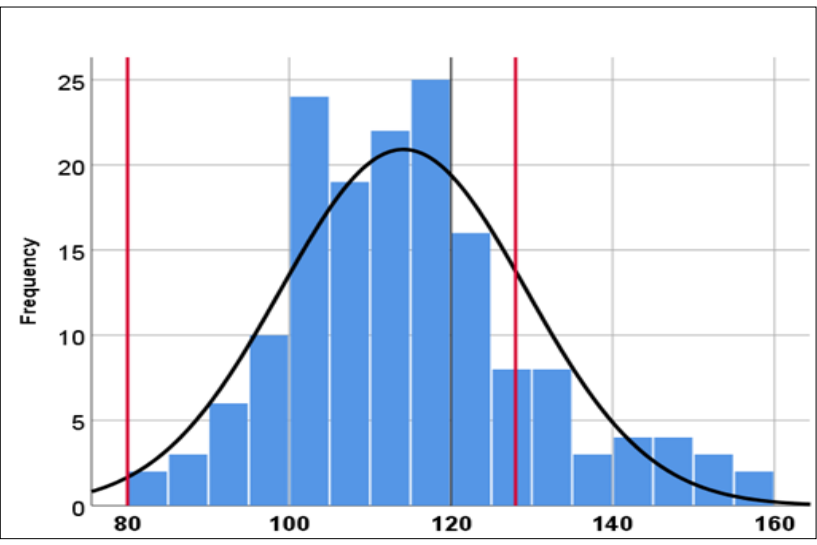

Fig 1 : Normal distribution of original IQ

We used the chi-square $(x 2)$ test to see the association of Prorated IQ of wasting, stunted, underweight and LBW children, normal children. So we found that there is no significant difference in IQ concerning anthropometric parameters and birth weight. We have nutritional data in the form of $24 \mathrm{hr}$ recall and food diversity, and we found no association of IQ with food diversity (p>0.05 for all).

The number of children in normal range according to original IQ was $135(85 \%)$, and in prorated, it changes to 144 (91\%).

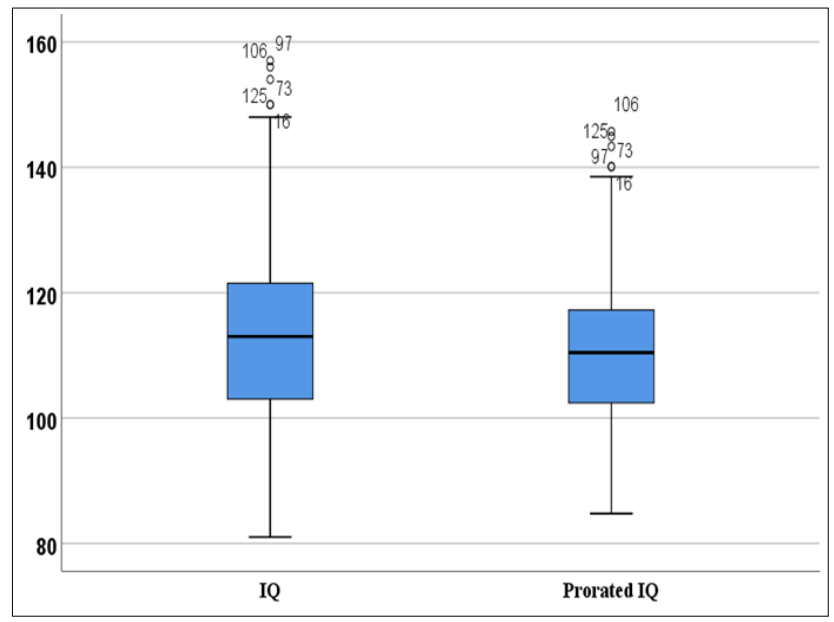

Fig 2. Normal distribution of prorated IQ

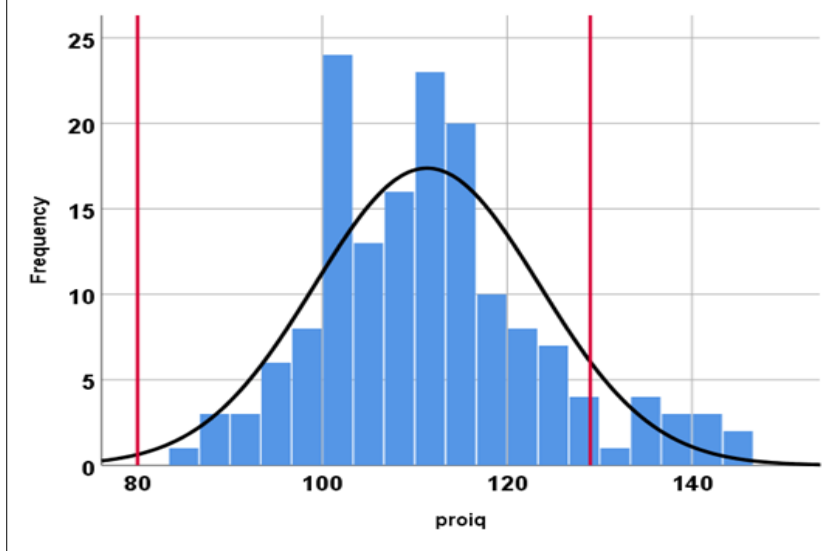

Fig 3. Median and interquartile range of $I Q$ and prorated IQ

Strength of this study- There are no reports about the intelligence of preschool in rural KONKAN in the literature. This study was our first attempt to get clues about cognition in young children of KONKAN area.

\section{Discussion}

We measured anthropometric parameters, recorded diet, and studied intelligence in a crosssection of preschool children from anganwadis in rural KONKAN. We found that there was no association in prorated IQ and birth weight as well as other anthropometric parameters. There is no significant difference between the prorated IQ of normal birth weight and LBW.

The human brain exhibits dramatic biological

Int. j. clin. biomed. res. 2020;6(2):30-34. 
development during the preschool years and roughly quadruples in weight before the age of six, when it has acquired approximately $90 \%$ of its adult volume. However, the preschool years are developmental period which leads to growth, expansion, "construction", and "blossoming" [9]. As per a study conducted in Africa (1), risk factors for developmental delay are inter-related, and the accumulation of risk has a long-term impact on child development. A systematic review by Linsell et al. [10] showed that male gender, lower birth weight, black race, lower education level of parents, and lower gestational age had been shown to be predictive of global cognitive dysfunction among young children.

The KONKAN region is characterized by mountainous terrain with poor soil quality, hot, humid weather, poverty, and fearful thoughts which have led to widespread malnutrition in the people. Our hospital is located in a remote rural area, so the study population is from the same rural area. One of our studies shows that $72 \%$ of adolescent were underweight. In another study, more than $65 \%$ of adolescent girls were zinc, calcium, and folate deficient. Hospital data shows that $41.9 \%$ of babies were LBW. A survey of cancer research from 2200 villages in KONKAN shows $51.7 \%$ population had low BMI, and only $4.5 \%$ were obese. So, we decided to evaluate IQ for the same community. These findings highlighted the leanness of the community of KONKAN. So, to trace it back we decided to assess intelligence and its association with body composition in preschool children [11].

We couldn't find any association of anthropometric parameters with IQ in children from rural villages in KONKAN in spite of a high prevalence of wasting and stunting and LBW. A possible explanation could be that the human fetus can adapt to undernutrition. Its responses include metabolic changes, redistribution of blood flow and changes in the production of fetal and placental hormones which control growth as stated by David Barker [12].

While slowing its rate of growth, the fetus may protect tissues that are important for immediate survival, the brain especially. One way in which the brain can be protected is by redistribution of blood flow to favour it [13]. This adaptation is known to occur in many mammals. However, in humans, it may have inflated costs for other tissues, notably the liver and other abdominal viscera, because of the large size of the brain [14]. This protective effect for the brain may explain normal or high IQ irrespective of poor anthropometric parameters in our study.

\section{Conclusion}

We could not find any association of anthropometric parameters with IQ despite a high prevalence of malnutrition.

Suggestions: There is a need to design a costeffective, user-friendly test to evaluate cognition and intelligence for rural children from 3 to 6 age group. Western countries use the StanfordBinet Fifth Edition (SB5) test for 3-6 years, and it has not been adapted for rural Indian children.

Acknowledgements: We thank the parents of the children who participated in the study.

Limitations: There are a few limitations to our report. Sampling was by convenience. The study was done on a small number of children. For dietary assessment, we just recorded a one-day nutritional recall. We did not quantify the food intake.

Author contribution: Dr Patil conceptualized the idea. Rupali Chavan and Swati Sonawane clinical psychologist carried out the cognitive testing Mohite worked on the diet component of the study. Joglekar, Omkar, Dnyanshwar, Pallavi handled the statistical aspects. Patil and Joglekar also drafted the manuscript.

\section{Conflict of interest : Nil Source of funding : Nil \\ REFERENCES}

1. Ford ND, Stein AD. Risk factors affecting child cognitive development: A summary of nutrition, environment, and maternal-child interaction indicators for sub-Saharan Africa J Dev Orig Health Dis. 2016;7(2):197-217

2. Almond D, Currie J. Killing me softly: The fetal origins hypothesis. The Journal of Economic Perspectives, 2011;25(3): 153-72

3. Sobaih BH. Long-term cognitive outcome of very low birth-weight Saudi preterm infants at the corrected age of 24-36 months. Saudi Med J 2018;39(4):368-72

4. Lee PA, Houk CP Cognitive and psychosocial development concerns in children born small for gestational age PediatrEndocrinol Rev PER. 2012;10(2):209-16

5. Hermida MJ, Shalom DE, Segretin MS, Goldin AP, Abril MC, Lipina SJ, Sigman M Risks for Child Cognitive Development in Rural Contexts. Front Psychol 2019;

6. Aninvestigation into the behavioural problems of plus two students with a view to develop an intervention plan. Chapter IV. Material and Methods. https://shodhganga.inflibnet. ac.in/bitstream/10603/110045/11/11_ chapter-4.pdf

7. Banglore NR, Kumble CN Binet Kamat Test for intelligence-issues with scoring and interpretation. Indian Journal of Mental Health 2016;3(4):504-5

Int. j. clin. biomed. res. 2020;6(2):30-34. 
8. Kaufman, Alan S. IQ Testing 101. New York: Springer Publishing. p. 112. ISBN 9780-8261-0629-2. Sattler, Jerome M. (2008). Assessment of Children: Cognitive Foundations. La Mesa (CA): Jerome M. Sattler, Publisher. inside back cover. ISBN 978-0-9702671-4-6. Lay summary (28 July 2010).

9. Brown TT, Jernigan TL Brain development during the preschool. Neuropsychol Rev. 2012; 22(4):313-33

10. Linsell L, Malouf R, Morris J, Mrlow $\mathrm{N}$ Prognostic factors for poor cognitive development in children born very preterm or with very low birth weight: A systematic review. JAMA Pediatr 2015;169:1162-72

11. Patil SN, Kadam S, Desai M, Joglekar $C$ Diabetes in the KONKAN region of India. World J Diabetes 2019; 10(1): 37-46

12. Barkar DJP. The malnourished baby and infant: Relationship with Type 2 diabetes. British Medical Bulletin. 2001;60 (1):69-88

13. Campbel AGM, Dawes GS, Fishman AP, Hyman Al. Regional redistribution of blood flow in the mature fetal lamb. Circ Res 1967; 21: 229-35

14. Fowden AL. Endocrine regulation of fetal growth. Reprod Fertil Dev1995; 7: 351-63. 